\title{
ANÁLISE QUALI-QUANTITATIVA DA ÁGUA CONDENSADA GERADA POR APARELHOS DE AR-CONDICIONADO
}

\section{QUALI-QUANTITATIVE ANALYSIS OF CONDENSED WATER GENERATED BY AIR- CONDITIONING APPLIANCES}

Jéssika Oliveira Neles Rodrigues

Mestranda no Programa de Pós-Graduação em Desenvolvimento e Meio Ambiente - Universidade Federal da Paraíba. (jessikaoliveiranr@gmail.com)

\section{Tarciso Cabral da Silva}

Universidade Federal da Paraíba. Doutorado em Engenharia Civil pela Universidade de São Paulo - POLI/USP (tarcisocabral@gmail.com)

\section{Gilson Barbosa Athayde Júnior}

Universidade Federal da Paraíba - Doutorado em Engenharia Civil (Saneamento) University of Leeds - Reino Unido. (gilson@ct.ufpb.br)

\section{Resumo}

O crescimento populacional, a poluição, o uso não racional e a distribuição desigual dos corpos hídricos e aquíferos acentuam a escassez hídrica, principalmente em regiões áridas e semiáridas. A fim de aumentar o leque de opções para o suprimento hídrico, surge a possibilidade do uso de fontes alternativas. Neste sentido, o aparelho de ar-condicionado é uma opção, pois opera de forma que ocorre a condensação do ar, gerando água, que é comumente desprezada. O presente trabalho analisou a viabilidade do uso da água condensada em aparelhos no órgão ambiental da Paraíba (SUDEMA) e a chance de se tornar uma fonte alternativa de água para usos não potáveis. Realizaram-se a coleta do volume e a análise físico-química e microbiológica da água gerada nestes aparelhos. Por meio da obtenção do consumo de água do edifício, foi possível comparar o volume obtido da condensação dos aparelhos com o volume consumido mensalmente no órgão, resultando numa capacidade de redução do consumo de água de até $7,5 \%$. Os parâmetros analisados foram comparados com as Classes de Reúso 1 e 3 do Manual de Conservação e Reúso da água em Edificações da Agência Nacional de Águas, obtendo-se resultados satisfatórios para o uso da água.

Palavras-Chave: escassez hídrica; fontes alternativas de água; qualidade da água.

\section{Abstract}

The population growth, the pollution, the non-rational use, and the uneven distribution of water bodies and aquifers, accentuating water scarcity, especially in arid and semi-arid regions. In order to increase the range of options for water supply, there is a possibility of using alternative sources. In this sense, the air conditioner operates in a way that air condensation occurs, generating water, which it commonly is despised. The present study analyzed the feasibility to use the condensed water of the equipment in the environment's organ of Paraiba (SUDEMA) and the possibility of becoming an alternative source of water for non-potable uses. The collect of the volume and the physical-chemical/microbiological analysis of the water generated in these devices were performed. By obtaining the water consumption of the building it was possible to compare the volume obtained from the condensation of the appliances with the volume consumed monthly in the organ resulting in a capacity to reduce water consumption of up to $7.5 \%$. The parameters analyzed were compared with the Reuse Classes 1 and 3 of the Manual de Conservação e Reuso da Água em Edificações da Agência Nacional de Águas, obtaining satisfactory results for the use of water.

Key words: water scarcity; alternative sources of water; water quality.

\section{INTRODUÇÃo}

A Política Nacional de Recursos Hídricos, Lei Federal 9.433 de 1997 (BRASIL, 1997), estabelece como um de seus objetivos assegurar a disponibilidade hídrica, nos padrões apropriados, para as atuais e futuras gerações. Para Gonçalves, Jordão e Januzzi (2009), as 
estruturas impróprias, falta de gestão adequada, juntamente com padrões culturais não racionais quanto ao uso da água contribuem para a escassez hídrica.

Nos centros urbanos, as demandas hídricas implicam em um elevado volume de água tratada, assim como a necessidade de maior infraestrutura para a distribuição. Além do comprometimento das águas superficiais, as fontes de águas subterrâneas, que são usadas por boa parte da população em municípios brasileiros, vêm sofrendo perda de produtividade em função da impermeabilização do solo, principalmente nos aglomerados urbanos e da alta demanda (HESPANHOL, 2003). Desta forma, fontes alternativas de água têm se tornado cada vez mais necessárias, sendo as que vêm despontando de forma mais contundente são as águas de chuva e as residuárias (reúso).

O crescimento das atividades econômicas e a manutenção das condições de qualidade de vida da população dependem da conscientização da importância do uso da água, considerada como um insumo estratégico, e do uso de forma racional por parte de todos os setores. Para tanto, são necessários investimentos em desenvolvimento tecnológico e a busca de soluções alternativas para a ampliação da oferta de água como, por exemplo, a utilização da água de reúso (ANA, 2005).

Por outro lado, a água residuária produzida por atividades humanas é parte do ciclo da gestão dos recursos hídricos, e, em sua maioria, é lançada nos corpos hídricos sem tratamento adequado, acarretando impactos negativos no meio ambiente e na saúde humana. Com a crescente produção destes efluentes, foi vista a oportunidade de transformar tal problemática em uma solução viável: o reúso das águas residuais (WWAP, 2017). De acordo com Aisse, Cohim e Kiperstok (2006), o reúso contribui efetivamente para redução da pressão sob mananciais e alivia o tratamento da água para fins potáveis. Assim, têm sido crescentes as iniciativas que buscam tornar viável a água residuária após o tratamento. No estado da Paraíba, por exemplo, no ano de 2015, foi promulgada a Lei Estadual № 10.559 (PARAÍBA, 2015), que estimula práticas de uso racional da água e instiga $o$ uso de fontes alternativas, como, por exemplo, o reúso de águas, tendo em vista a escassez hídrica.

A escassez hídrica nos centros urbanos, principalmente em decorrência do baixo volume dos mananciais, que tem ocorrido com frequência nas últimas décadas em cidades brasileiras, tem induzido o aumento do número de instalações de aproveitamento da água de chuva nas edificações, prática que pode representar uma importante complementação ao abastecimento público.

Outra fonte alternativa a ser considerada é a água condensada proveniente das máquinas de ar-condicionado. Os sistemas de ar-condicionado trazem conforto térmico à população, além de possibilitar a refrigeração de ambientes que assim necessitem.

Segundo Rigotti (2014), a água condensada a partir dos aparelhos de ar-condicionado, em sua maioria, é descartada de forma ineficaz, acarretando a proliferação de mosquitos em pequenas poças de água e gotejamento em passagens de pedestres. Em alguns casos, a água condensada é direcionada por drenos para - sistema de esgoto ou de águas pluviais, gerando maior demanda para as infraestruturas de saneamento, já que acresce a vazão nas estações de tratamento de esgoto e nos sistemas de águas pluviais.

Para Sousa et al. (2016), o volume da água condensada sofre interferência direta da potência do aparelho, do teor de umidade e área do ambiente refrigerado e da movimentação de entrada e saída de pessoas no local, o que pode vir a causar aumento da temperatura do ambiente e, consequentemente, requerer maior carga de trabalho para o aparelho.

Alguns estudos têm sido desenvolvidos no Brasil visando quantificar e investigar sobre a qualidade da água de condensação. Catapreta e Freitas (2017) realizaram um estudo sobre a viabilidade para aproveitamento da água de condensação de máquinas de ar-condicionado na cidade administrativa do estado de Minas Gerais, em Belo Horizonte, e demonstrou que os volumes captados variaram de 7 a $9,31 \mathrm{~m}^{3}$ por dia no período analisado, possibilitando, em conjunto com medidas de conscientização e ajuste nas instalações, uma diminuição de $14,06 \%$ da água fornecida pela concessionária.

Lima et. al., (2017) realizaram um projeto para aproveitamento de águas condensadas de aparelhos de ar-condicionado na cidade de Cajazeiras, Paraíba, onde foi possível verificar a acumulação de 4,2L de água, para cada aparelho, no regime de funcionamento de 10 horas por dia, viabilizando a utilização de $10 \mathrm{~m}^{3} \mathrm{mês}^{-1}$ de água para utilização nas descargas sanitárias, limpeza de salas, irrigação de jardim, 
entre outras.

No estudo efetuado por Rocha (2017), no Centro de Tecnologia da Universidade Federal do Rio Grande do Norte, a coleta da água condensada foi efetuada em aparelhos com potência entre 7.000 BTU e 22.000 BTU, obtendo como resultado médio a vazão de aproximadamente $1 \mathrm{Lh}^{-1}$. A oferta diária de água condensada, a partir dos 108 aparelhos de arcondicionado da edificação, seria de $896,5 \mathrm{Ldia}^{-1}$, em que, caso houvesse o aproveitamento, tal volume poderia representar $89,5 \%$ do uso de água para fins de irrigação da vegetação no entorno do prédio.

Ainda sobre a obtenção de água por condensação, alguns equipamentos têm sido desenvolvidos a partir da umidade do ar. O dispositivo, por exemplo, criado pelos pesquisadores da Universidade de Engenharia e Tecnologia (UTEC) de Lima e pela agência de propaganda Mayo Peru DraftFCB captura a umidade do ar e, com a ajuda de condensadores e filtros, produz a água em uma estrutura tipo Outdoor. A água é armazenada em tanques no topo da estrutura e, depois de filtrada, desce por um tubo conectado a uma torneira, acessível a todos, com a produção de 96 litros por dia (PORTAL O TEMPO, 2013).

Outro equipamento, criado pelo brasileiro Pedro Paulino, que obtém água condensada através da umidade do ar, é o Water Air. Este dispositivo possui turbinas que aspiram o ar para dentro da máquina e, em seguida, as moléculas de água são condensadas em placas resfriadas. Para a purificação, são utilizados filtros e raios ultravioletas, além de receber sais minerais por meio de outro filtro. Existem dois modelos deste aparelho no mercado, um que chega a gerar $30 \mathrm{~L}$ de água por dia e o maior, 5000L (SOUZA, 2014).

A turbina eólica, desenvolvida pela empresa Dutch Rainmaker, utiliza a energia gerada pelos ventos para produzir água por condensação da umidade do ar. A diferença para as turbinas tradicionais está nos tanques de água acoplados na parte inferior da torre. A turbina aciona quatro compressores. Quando o ar é forçado através dos permutadores de calor e resfriado, a água contida no ar se condensa e as gotas que se formam são coletadas pelos tanques. Em seguida, a água é mineralizada e pode ser utilizada para consumo humano ou para agricultura. A turbina consegue produzir uma média de 7.500 litros de água diariamente, dependendo da umidade relativa do ar (CAMARGO, 2014).
Nessa linha, o equipamento denominado WaterSeer lança mão do resfriamento do ar movido para uma câmara de condensação no subsolo por meio de uma turbina, devido ao vento na superfície. As laterais de metal da câmara subterrânea do aparelho são resfriadas pelo contato com o solo, o que gera as condições para a condensação e armazenamento da água em um reservatório inferior acoplado. O aparelho funciona continuamente produzindo $37 \mathrm{~L}$ de água pura por dia, de acordo com a umidade relativa do ar (PORTAL TRATAMENTO DE ÁGUA, 2016).

No Peru, região de Lima, Abel Cruz desenvolveu um sistema simples que consiste na instalação de painéis feitos com redes de nylon, os quais capturam a água suspensa no ar por condensação, e as pequenas gotas formadas escoam pela rede e são levadas por canaletas até um reservatório maior. Através deste processo, diariamente, estão sendo estocados de 200 a 400 litros de água, para usos não potáveis, dependendo das dimensões da instalação (CAMARGO, 2016).

\section{Água oriunda do processo de condensação}

A evaporação da água de rios, oceanos e a transpiração de animais e vegetais, entre outros, são fenômenos responsáveis pela água presente no ar atmosférico, sendo formado por vapor d'água e gases, especialmente nitrogênio e oxigênio. As moléculas de água presentes no ar podem ser removidas a partir de processos termodinâmicos, como quando a água encontra uma superfície gelada o bastante para a condensação (AQUINO, 2018).

A condensação é o processo físico da transformação da matéria no estado gasoso para o líquido. Também chamada de liquefação, é o procedimento inverso da vaporização. Para que o vapor sofra condensação, é necessário que ocorra ou uma redução na sua temperatura ou um aumento na pressão a que está submetido.

Há vários tipos de aparelhos de arcondicionado no mercado, contudo, o princípio dos sistemas de refrigeração segue o mesmo procedimento. Tais equipamentos usam o mecanismo de refrigeração a partir da troca de temperatura com o ambiente. $\mathrm{O}$ ar passa através das serpentinas do evaporador, local onde se faz presente o fluído refrigerante, que resfria o ar de acordo com a temperatura definida. Estas serpentinas são mantidas a uma temperatura inferior ao ponto de orvalho, logo, quando o vapor 
d'água presente no ar entra em contato com estas superfícies, ocorre o processo de condensação (CALDAS; CAMBOIM, 2017). A figura 1 ilustra como acontece tal processo no interior do aparelho de ar-condicionado.

Após a condensação, a água é direcionada para a tubulação de dreno e escoa para o ambiente externo. A quantidade de água que é gerada por este processo depende diretamente das condições de umidade do ar, pois quanto maior for o número de moléculas de água no ar, maior será a quantidade de água gerada. 0 aparelho de ar-condicionado é projetado para a climatização de ambientes, ocorrendo o processo que desumidifica o ar. Deste modo, a água residuária proveniente deste processo não é produzida para ser limpa e potável (BASTO; CASSINI; FRANCI, 2015)

Postos o fomento pelas fontes alternativas de água e a possibilidade da geração de água pelo processo de condensação, neste trabalho, foi realizada uma avaliação quali-quantitativa da água condensada de aparelhos de arcondicionado do tipo split, instalados no edifício da Superintendência de Administração do Meio Ambiente do estado da Paraíba, visando à sua utilização como fonte alternativa para uso não potável no âmbito do edifício.

\section{Figura 1: Diagrama do sistema de condensação de água na serpentina}

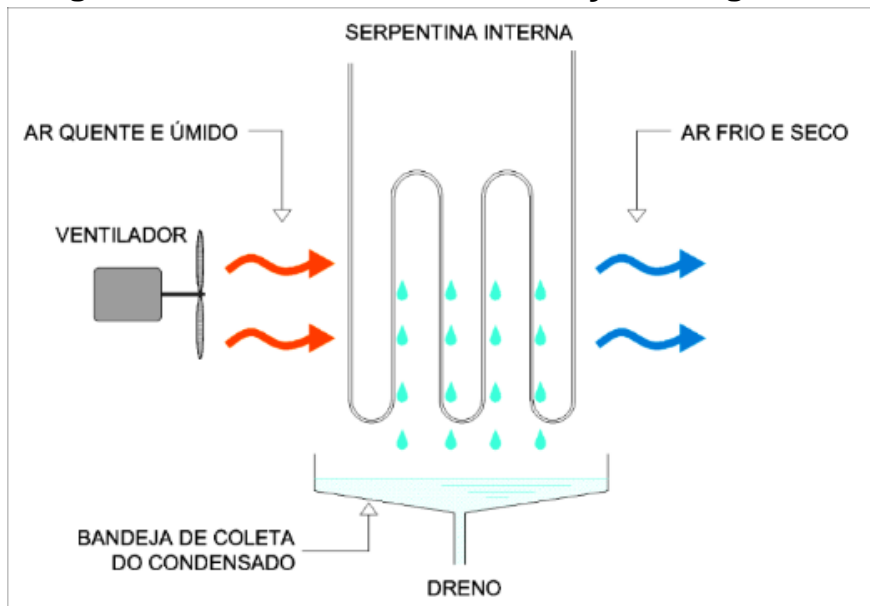

Fonte: Acervo da NB Projetos Ltda., 2011 apud Bastos e Calmon (2012).

\section{METODOLOGIA}

O local escolhido para as análises quantitativas e qualitativas das águas condensadas em aparelhos de ar-condicionado foi o prédio sede do órgão ambiental da Paraíba, a Superintendência de Administração do Meio Ambiente (SUDEMA), localizado em João Pessoa, capital do estado.

A cidade de João Pessoa possui uma temperatura média em torno de $26,1^{\circ} \mathrm{C}$. O mês de fevereiro é característico por ser o de maior temperatura, com $27,2^{\circ} \mathrm{C}$, e julho o de menor, em torno de $24,2^{\circ} \mathrm{C}$ (WEATHERBASE, 2019). A estrutura construtiva da SUDEMA não possui atributos para utilização de ventilação natural, o que poderia resultar em maior conforto térmico. Dessa forma, o órgão dispõe de sistemas de climatização com aparelhos de ar-condicionado do tipo split em todas as suas salas, para a melhoria do bem-estar dos funcionários e usuários e para a proteção de equipamentos sensíveis à temperatura mais elevada.

Para início das análises quantitativas do volume de água condensada, foram realizadas visitas in loco a todos os setores da sede da SUDEMA, sendo feita a apuração de quantos aparelhos cada sala possuía, qual a potência em BTU e quantas horas diárias cada aparelho permanece operando. Foram quantificados um total de cinquenta e sete aparelhos com potências variadas: $7.000 \mathrm{BTU}, 10.000 \mathrm{BTU}, 12.000 \mathrm{BTU}$, 16.000 BTU, 18.000 BTU e 30.000 BTU.

A coleta da vazão de água condensada foi feita em cinco pontos durante cinco dias. Os pontos de coleta foram definidos de acordo com a potência do aparelho e o tempo de funcionamento (ver Tabela 1). Foram utilizados como recipientes de coleta garrafas PETs de 1,5 e 2 litros, devidamente etiquetadas. $\mathrm{Na}$ Coordenadoria de Medições Ambientais (CMA), laboratório da SUDEMA, mediu-se o volume de cada coleta com 
o uso de uma proveta volumétrica de $1000 \mathrm{~mL}$ (Figura 2).

Os recipientes usados para as coletas foram distribuídos e acomodados nos drenos de cada ponto já pré-estabelecido. Iniciada a coleta dos volumes, anotaram-se o horário de início e a temperatura na qual 0 aparelho de arcondicionado encontrava-se no momento. Após cerca de 60 minutos, o horário final exato da coleta era registrado, os recipientes retirados dos pontos de coleta e levados ao CMA (laboratório). No Ponto 2, onde a vazão se mostrou bastante elevada em comparação com os outros pontos, 0 recipiente era retirado após cerca de 30 minutos de coleta, uma vez que haveria o risco de transbordo e a amostra seria perdida. Nas
Figuras 3, 4, 5, 6 e 7, temos todos os pontos de coleta do volume.

Para análise físico-química e microbiológica, foram definidos três pontos de coleta, escolhidos de acordo com o ambiente em que estão localizados os aparelhos condensadores de ar ou com o volume gerado, averiguado anteriormente pela análise quantitativa (Tabela 2). Analisaramse os parâmetros no CMA utilizando técnicas de acordo com Standard Methods for Examination of Water and Wastewater.

As coletas das análises qualitativas foram efetuadas em recipientes apropriados, disponibilizados pelo laboratório da SUDEMA, devidamente esterilizados. Nas Figuras 8, 9 e 10, têm-se os pontos de coleta.

Tabela 1: Pontos de coleta da vazão da água condensada

\begin{tabular}{|c|c|c|c|c|}
\hline $\begin{array}{c}\text { Ponto de } \\
\text { coleta }\end{array}$ & $\begin{array}{c}\text { Potência } \\
\text { [BTU] }\end{array}$ & $\begin{array}{c}\text { Tempo de } \\
\text { funcionamento } \\
\text { diário [hora] }\end{array}$ & Localização (Setor) & $\begin{array}{c}\text { Motivação da } \\
\text { escolha }\end{array}$ \\
\hline Ponto 1 & 18.000 & 24 & $\begin{array}{c}\text { Centro de Processamento } \\
\text { de Dados }\end{array}$ & $\begin{array}{c}\text { Opera 24 horas } \\
\text { diariamente }\end{array}$ \\
\hline Ponto 2 & 30.000 & 8 & Centro de Documentação & $\begin{array}{c}\text { Maior potência entre } \\
\text { os aparelhos }\end{array}$ \\
\hline Ponto 3 & 12.000 & 8 & Divisão de Atendimento & $\begin{array}{c}\text { Potência mais } \\
\text { recorrente }\end{array}$ \\
\hline Ponto 4 & 12.000 & 8 & $\begin{array}{c}\text { Centro de Documentação } \\
\text { (recepção) }\end{array}$ & $\begin{array}{c}\text { Potência mais } \\
\text { recorrente }\end{array}$ \\
\hline Ponto 5 & 9.000 & 8 & $\begin{array}{c}\text { Coordenadoria de Mediçães } \\
\text { Ambientais }\end{array}$ & $\begin{array}{c}\text { Segunda potência } \\
\text { mais recorrente }\end{array}$ \\
\hline
\end{tabular}

Fonte: Autor, 2018.

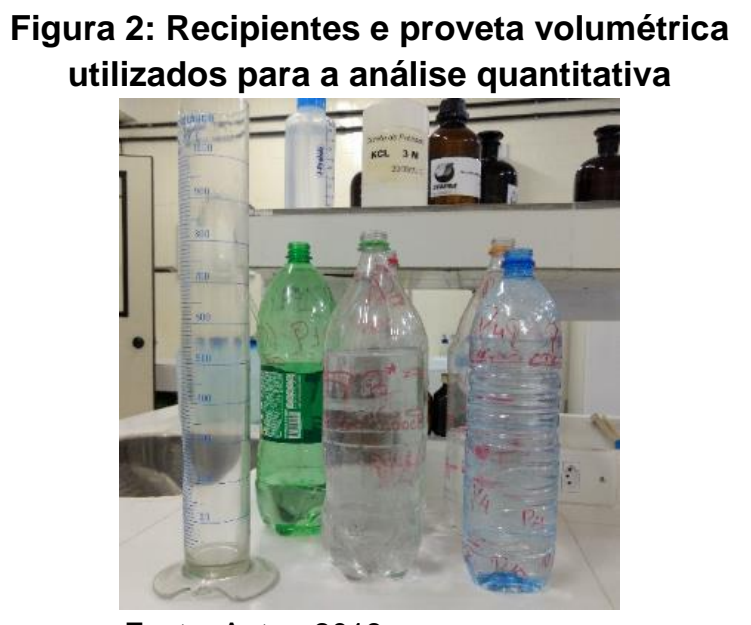

Fonte: Autor, 2018. 
Figura 3: Ponto 1 de coleta da vazão

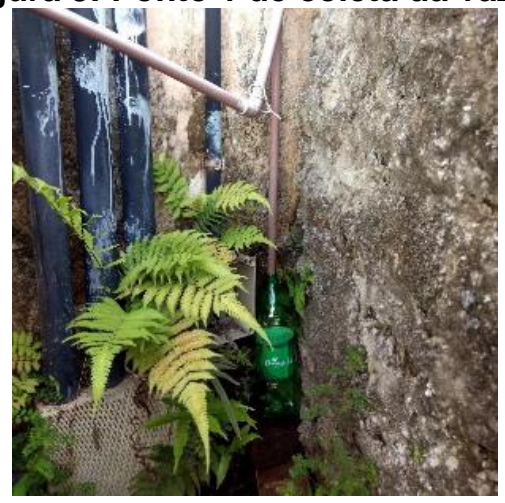

Fonte: Autor, 2018.

Figura 5: Ponto 3 de coleta da vazão

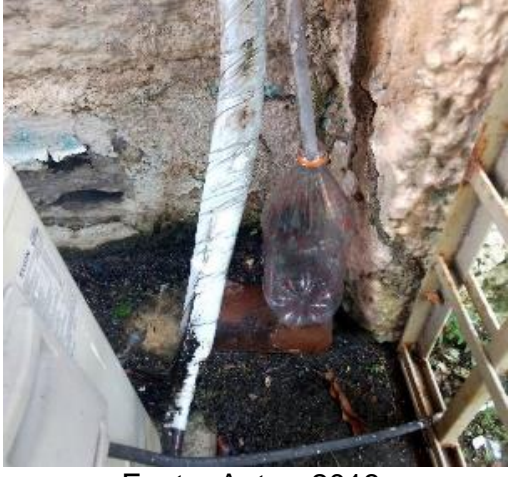

Fonte: Autor, 2018.
Figura 4: Ponto 2 de coleta da vazão

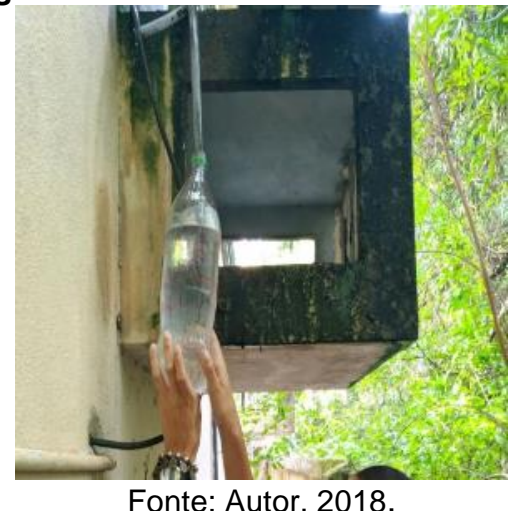

Figura 6: Ponto 4 de coleta da vazão

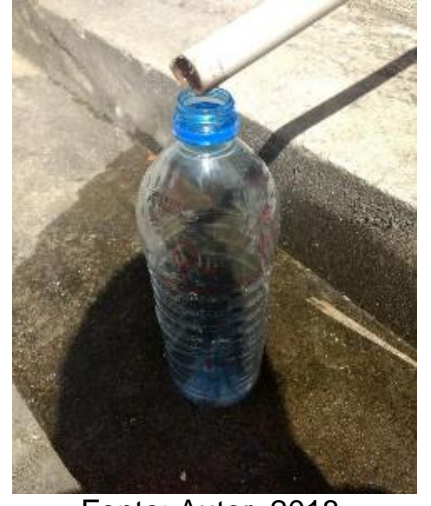

Fonte: Autor, 2018

Figura 7: Ponto 5 de coleta da vazão

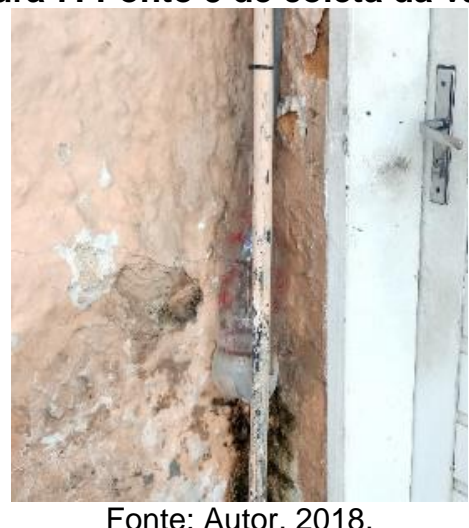

Fonte: Autor, 2018

Figura 8: Ponto 1 coleta da análise qualitativa

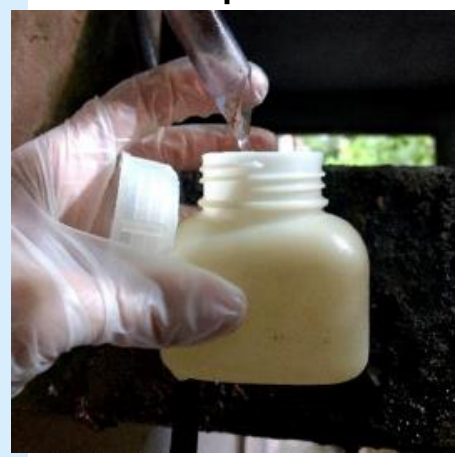

Fonte: Autor, 2018
Figura 9: Ponto 2 coleta da análise qualitativa

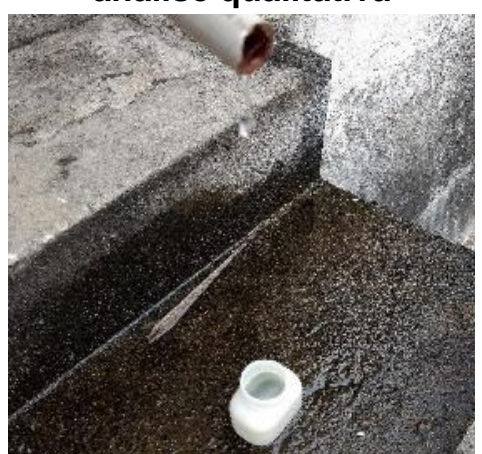

Fonte: Autor, 2018
Figura 10: Ponto 3 coleta da análise qualitativa

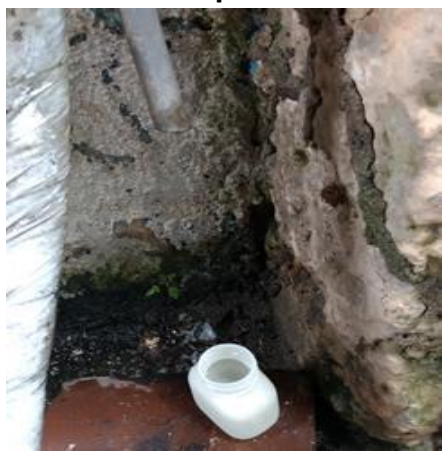

Fonte: Autor, 2018 
Tabela 2: Pontos de coleta da análise físico-química e microbiológica

\begin{tabular}{c|c|c|c}
\hline Ponto de coleta & Potência [BTU] & Localização (Setor) & Motivação da escolha \\
\hline Ponto 1 & 30.000 & $\begin{array}{c}\text { Centro de } \\
\text { Documentação }\end{array}$ & Maior vazão gerada por hora \\
\hline Ponto 2 & 12.000 & $\begin{array}{c}\text { Centro de } \\
\text { Documentação }\end{array}$ & $\begin{array}{c}\text { Pouca movimentação de } \\
\text { pessoas }\end{array}$ \\
\hline Ponto 3 & 12.000 & Divisão de Atendimento & Muita movimentação de pessoas \\
\hline
\end{tabular}

Fonte: Autor, 2018.

Os resultados dos parâmetros analisados foram comparados com os padrões do Manual de Conservação e Reúso da água em Edificações (ANA, 2005), para água de reúso da Classe 1 (descargas em bacias sanitárias, lavagem de pisos, fins ornamentais e lavagem de roupas e veículos) e Classe 3 (irrigação de áreas verdes e rega de jardins), pois tais classes são as que abordam atividades pertinentes à SUDEMA. A concessionária de abastecimento de água do estado da Paraíba (CAGEPA) é a empresa responsável por todo abastecimento de água no prédio-sede da SUDEMA, portanto, a partir das faturas da concessionária, foi possível a obtenção do consumo de água. Utilizou-se o período de janeiro de 2017 a abril de 2018 para o levantamento do consumo de água na SUDEMA.

\section{RESULTADOS E DISCUSSÕES}

\section{Vazão da água condensada}

O Ponto 1 , referente ao aparelho de arcondicionado que opera 24 horas diárias, não foi levado em consideração na análise estatística, visto seu funcionamento contínuo (a vazão sofre inferência por tal característica). Para o cálculo das vazões diárias, levou-se em consideração a quantidade de horas que cada aparelho funciona por dia.

O volume mensal gerado foi calculado considerando que o órgão opera de segunda a quinta-feira em dois turnos e um turno às sextasfeiras, totalizando cerca de 18 dias por mês. Para os aparelhos do órgão com funcionamento contínuo, foram considerados 30 dias de funcionamento no mês.

O Gráfico 1 revela que quanto maior a potência, maior volume de água condensada pelo aparelho será provável. Com base no Gráfico 1, foi construída a Equação 1 , que rege 0 comportamento da curva para o cálculo da vazão de água condensada pelos aparelhos que operam durante 8 horas diariamente.

$$
Q=0,8567 e^{-0,00004 P} \quad\left(\mathrm{r}^{2}=0,9999\right)
$$

Onde:

$\mathrm{Q}=$ Vazão $\left[\mathrm{Lh}^{-1}\right]$;

$\mathrm{P}=$ Potência do aparelho de arcondicionado [BTU]

Tabela 3: Vazão média dos pontos de coleta

\begin{tabular}{c|c|c|c}
\hline Potência [BTU] & Quantidade de pontos coletados & Vazão $\left[\mathrm{Lh}^{-1}\right]$ & Vazão $\left[\mathrm{m}^{3} \mathrm{~h}^{-1}\right]$ \\
\hline 9.000 & 1 & 1,24 & 0,00124 \\
\hline 12.000 & 2 & $1,41^{\star *}$ & 0,00141 \\
\hline $18.000^{*}$ & 1 & 0,44 & 0,00044 \\
\hline 30.000 & 1 & 2,97 & 0,00297 \\
\hline
\end{tabular}

*Opera 24 horas diárias, 7 dias por semana

**Média das vazões dos dois pontos com aparelhos de 12.000 BTU.

Fonte: Autor, 2018. 
Gráfico 1: Potência versus vazão média para aparelho split com funcionamento de 8 horas diárias

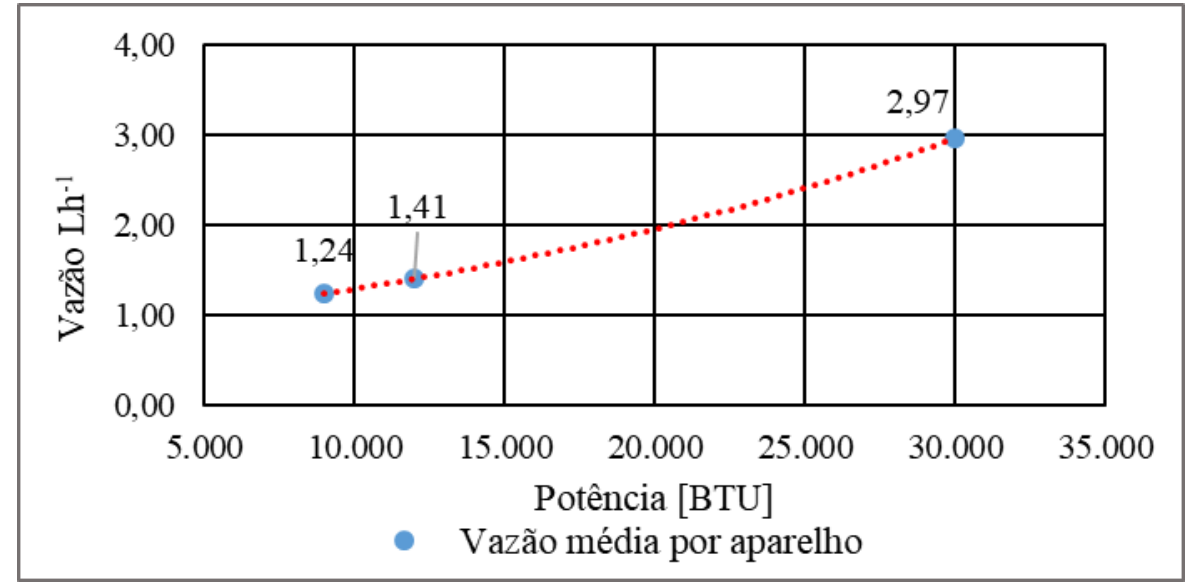

Fonte: Autor, 2018.

Os aparelhos de 7.000 BTU, 10.000 BTU, 16.000 BTU e 18.000 BTU possuem potências, ou tempo de funcionamento diário (no caso específico do aparelho de 18.000 BTU), distintas dos aparelhos que foram pontos de coleta, sendo as vazões horárias destes aparelhos calculadas a partir da Equação 1 (Tabela 4).

Um aparelho de 12.000 BTU, que opera 24 horas diárias no laboratório da SUDEMA, foi desconsiderado nos cálculos, não sendo possível a coleta da vazão do mesmo, pois, por atuar continuamente, o ambiente que este climatiza tende a possuir baixa umidade, pendenciando 0 volume gerado.

Com os valores apresentados na Tabela 4, foi possível a quantificação total da água condensada gerada diariamente pelos aparelhos da instituição, de acordo com a potência de cada um (Tabela 5).

Para efeito de cálculo, foi considerado que tais aparelhos possuem comportamentos análogos; portanto, com as vazões diárias obtidas na Tabela 5 e quantidade de dias de trabalho, foram obtidos os valores da Tabela 6 .

O volume de água condensada pelos aparelhos de ar-condicionado da SUDEMA foi estimado em um total $11.691,54$ Lmês $^{-1}$, ou $11,69 \mathrm{~m}^{3}$ mês $^{-1}$. Visto que o órgão ambiental funciona durante os 12 meses do ano, o volume anual pode chegar a $140.298,43$ Lano $^{-1}\left(140 \mathrm{~m}^{3}\right.$ ano $\left.^{-1}\right)$.

Tabela 4: Vazão horária, gerada pela equação 1, dos aparelhos de ar-condicionado da SUDEMA

\begin{tabular}{c|c|c}
\hline Potência [BTU] & Vazão $\left[\mathrm{Lh}^{-1}\right]$ & Vazão $\left[\mathrm{m}^{3} \mathrm{~h}^{-1}\right]$ \\
\hline 7.000 & $1,13^{* *}$ & 0,00113 \\
\hline 9.000 & 1,24 & 0,00124 \\
\hline 10.000 & $1,28^{* *}$ & 0,00128 \\
\hline 12.000 & 1,41 & 0,00141 \\
\hline $12.000^{*}$ & - & - \\
\hline 16.000 & $1,62^{* *}$ & 0,00162 \\
\hline $18.000^{*}$ & 0,44 & 0,00044 \\
\hline 18.000 & $1,76^{* *}$ & 0,00176 \\
\hline 30.000 & 2,97 & 0,00297 \\
\hline
\end{tabular}

* Opera 24 horas diárias, 7 dias por semana

** Valor obtido pela Equação 1

Fonte: Autor, 2018. 
Tabela 5: Vazão diária dos aparelhos de ar-condicionado da SUDEMA

\begin{tabular}{|c|c|c|c|c}
\hline Potência [BTU] & Quantidade de aparelhos & $\begin{array}{c}\text { Somatória das horas de } \\
\text { funcionamento por dia }\end{array}$ & Vazão [Ldia $\left.{ }^{-1}\right]$ & Vazão $\left[\mathrm{m}^{3} \mathrm{dia}^{-1}\right]$ \\
\hline 7.000 & 2 & 12 & 13,60 & 0,0136 \\
\hline 9.000 & 12 & 78 & 96,77 & 0,0967 \\
\hline 10000 & 1 & 8 & 10,22 & 0,0102 \\
\hline 12.000 & 29 & 217 & 306,36 & 0,3063 \\
\hline 16.000 & 1 & 8 & 13,00 & 0,0129 \\
\hline $18.000^{*}$ & 1 & 24 & 10,53 & 0,0105 \\
\hline 18.000 & 9 & 8 & 14,08 & 0,0141 \\
\hline 30.000 & 1 & 60 & 177,94 & 0,1779 \\
\hline
\end{tabular}

* Opera 24 horas diárias, 7 dias por semana

Fonte: Autor, 2018

Tabela 6: Vazão mensal dos aparelhos de ar-condicionado da SUDEMA

\begin{tabular}{|c|c|c|c}
\hline Potência [BTU] & $\begin{array}{c}\text { Dias de funcionamento por } \\
\text { mês }\end{array}$ & Volume mensal (L) & Volume mensal $\left(\mathrm{m}^{3}\right)$ \\
\hline 7.000 & 18,0 & 244,84 & 0,24 \\
\hline 9.000 & 18,0 & 1741,89 & 1,74 \\
\hline 10000 & 18,0 & 184,04 & 0,18 \\
\hline 12.000 & 18,0 & 5514,40 & 5,51 \\
\hline 16.000 & 18,0 & 233,96 & 0,23 \\
\hline $18.000^{*}$ & 30,0 & 315,96 & 0,32 \\
\hline 18.000 & 18,0 & 253,44 & 0,25 \\
\hline 30.000 & 18,0 & 3203,00 & 3,20 \\
\hline & TOTAL & $\mathbf{1 1 . 6 9 1 , 5 4}$ & $\mathbf{1 1 , 6 9}$ \\
\hline
\end{tabular}

* Opera 24 horas diárias, 7 dias por semana Fonte: Autor, 2018.

\section{Consumo de água na instituição}

Calculada a média de consumo mensal na SUDEMA nos últimos 14 meses, obteve-se o valor de $157 \mathrm{~m}^{3} \mathrm{mês}^{-1}$, e, sendo de $11,69 \mathrm{~m}^{3} \mathrm{mês}^{-1} \mathrm{a}$ vazão de água condensada gerada pelos aparelhos de ar-condicionado, tem-se que, promovendo o aproveitamento desta água, podese vir a reduzir em até $7,5 \%$ consumo de água oriunda da concessionária de água, tendo, portanto, uma economia também de dinheiro público.

Em razão do tempo e instrumentos insuficientes do presente trabalho, a análise das possíveis perdas de água por vazamentos (visíveis e/ou invisíveis) não foi exequível, logo, o valor médio de consumo mensal de água potável pode conter possíveis perdas de água existentes no órgão e que são contabilizadas como consumo à concessionária.

\section{Qualidade da água}

Os resultados dos parâmetros físicoquímicos e microbiológico das águas condensadas pelos três aparelhos de arcondicionado analisados mostraram qualidade satisfatória quando comparados com os padrões estabelecidos para as classes de água de reúso 1 (uso para descargas de bacias sanitárias, lavagem de pisos, fins ornamentas, lavagem de 
roupa e veículos) e 3 (uso para irrigação de áreas verdes e rega de jardins) do Manual de Conservação e Reúso da Água em Edificações (ANA, 2005).

Para os parâmetros físico-químicos analisados, em todos os pontos, a qualidade da água foi compatível com os padrões recomendados pela ANA (2005).

Os valores máximos obtidos para a cor nas análises foi de $9 u \mathrm{H}$, estando abaixo dos padrões estabelecidos pela ANA (2005), para as classes 1 e 3 de reúso, como podemos ver no Gráfico 2.

No Gráfico 2, pode-se notar que os valores para o parâmetro cor, nos pontos 1 e 3, chegaram próximos do estabelecido para a classe 1, mas ainda se enquadram dentro do padrão para o reúso. Um aspecto que pode ter influenciado este parâmetro é o meio pelo qual a água é transportada, pois, no momento das coletas, notou-se que os pontos 1 e 3 possuem mais resíduos em seu dreno do que o ponto 2 , o que influencia na qualidade da água.

O resultado da análise da turbidez nas águas condensadas pelos aparelhos de climatização da SUDEMA está representado pelo Gráfico 3.

\section{Gráfico 2: Resultado do parâmetro cor}

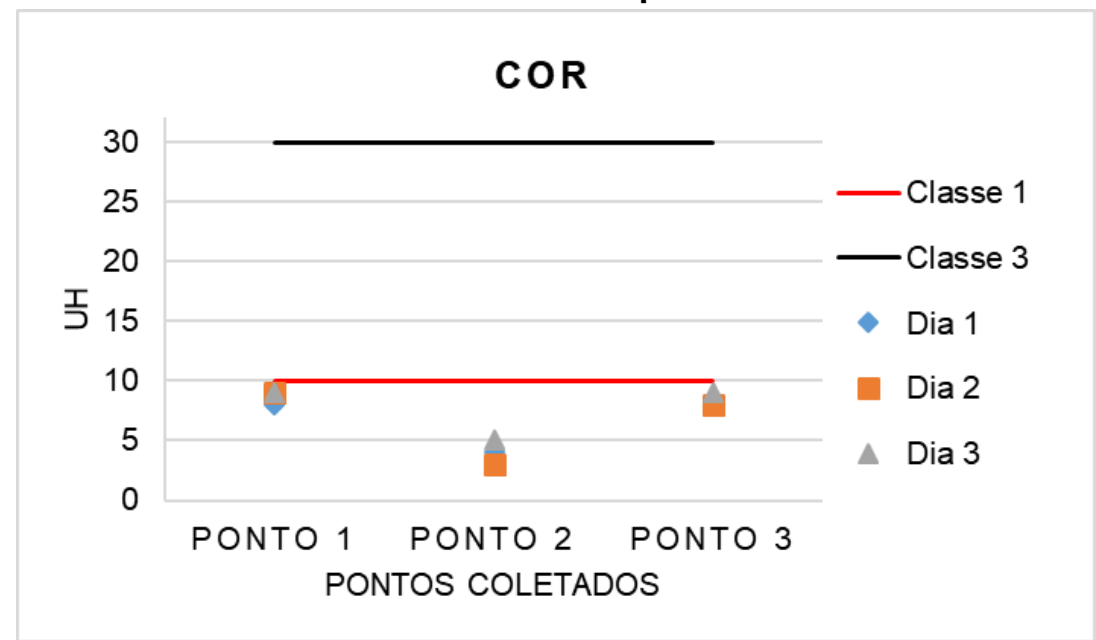

Fonte: Autor, 2018

Gráfico 3: Resultado e comparação do parâmetro

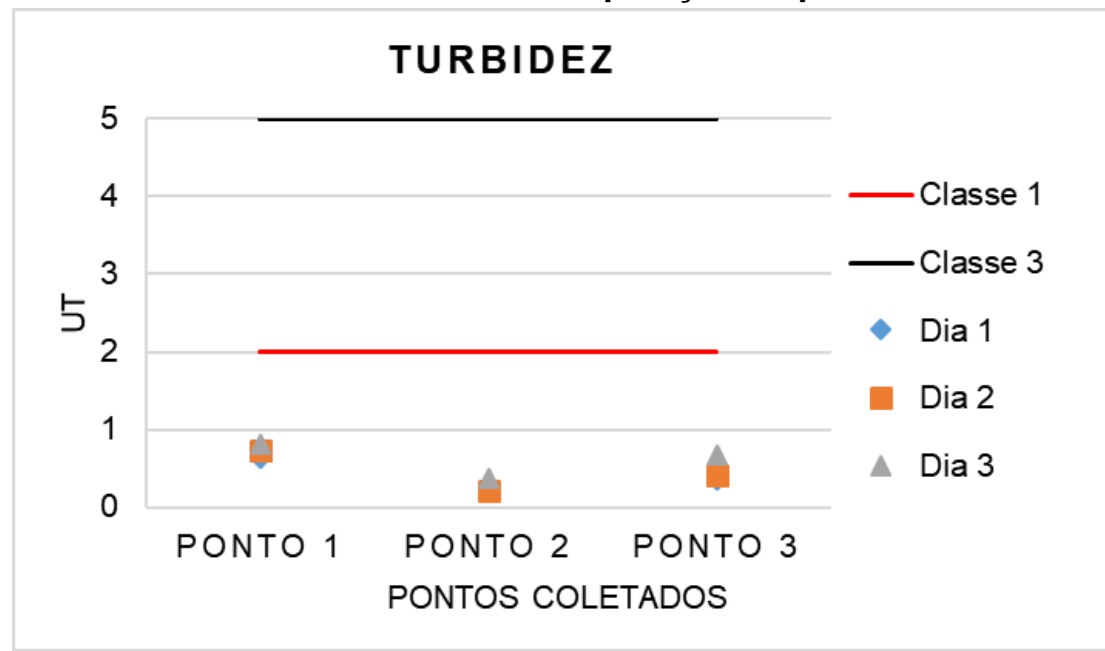

Fonte: Autor, 2018.

A turbidez apresentou valores aproximados nos três pontos de coleta, todos abaixo dos padrões estabelecidos pela ANA (2005). No estudo de Nóbrega (2015), a média da turbidez, em águas condensadas, foi de 0,45uT e, para
Sousa, Oliveira e Coelho (2016), de 0,02uT, estando estes valores em conformidade aos encontrados nas análises dos aparelhos de arcondicionado da SUDEMA. 
$\mathrm{O} \mathrm{pH}$ das amostras de água se mostrou satisfatório comparado com o intervalo entre os padrões máximo e mínimo, para as classes 1 e 3 , estabelecidos pela ANA (2005), como vemos no gráfico 4.

Os valores do $\mathrm{pH}$, em todos os três pontos de coleta, mantiveram-se dentro do intervalo considerado neutro de 6,5 e 7,5. O valor médio, para águas condensadas analisadas por Nóbrega (2015), foi de 7,15. Para Carvalho, Cunha e Faria (2012), este parâmetro manteve-se no intervalo de 7,03 a 7,34. Tais valores, encontrados na bibliografia, se aproximam aos números obtidos no presente trabalho e pertencem ao intervalo neutro de $\mathrm{pH}$.

Segundo Carvalho, Cunha e Faria (2012), a condutividade elétrica na água condensada por aparelhos de ar-condicionado refere-se ao aspecto de íons presentes vindos do sistema de condensação do equipamento. Para este parâmetro, não há padrões estabelecidos, contudo, para as classes de reúso 1 e 3 do Manual da ANA (2005), foi feita a análise deste parâmetro nas águas coletadas, exposta no gráfico 5.

Gráfico 4: Resultado e comparação do parâmetro pH

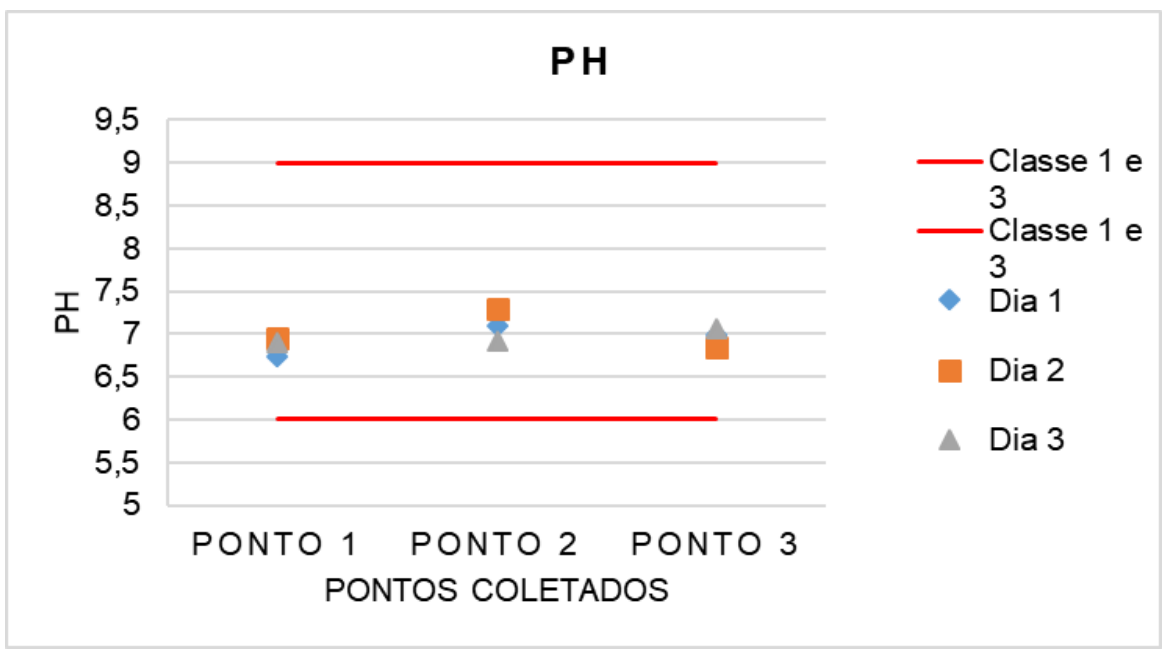

Fonte: Autor, 2018.

Gráfico 5: Resultado e comparação do parâmetro condutividade

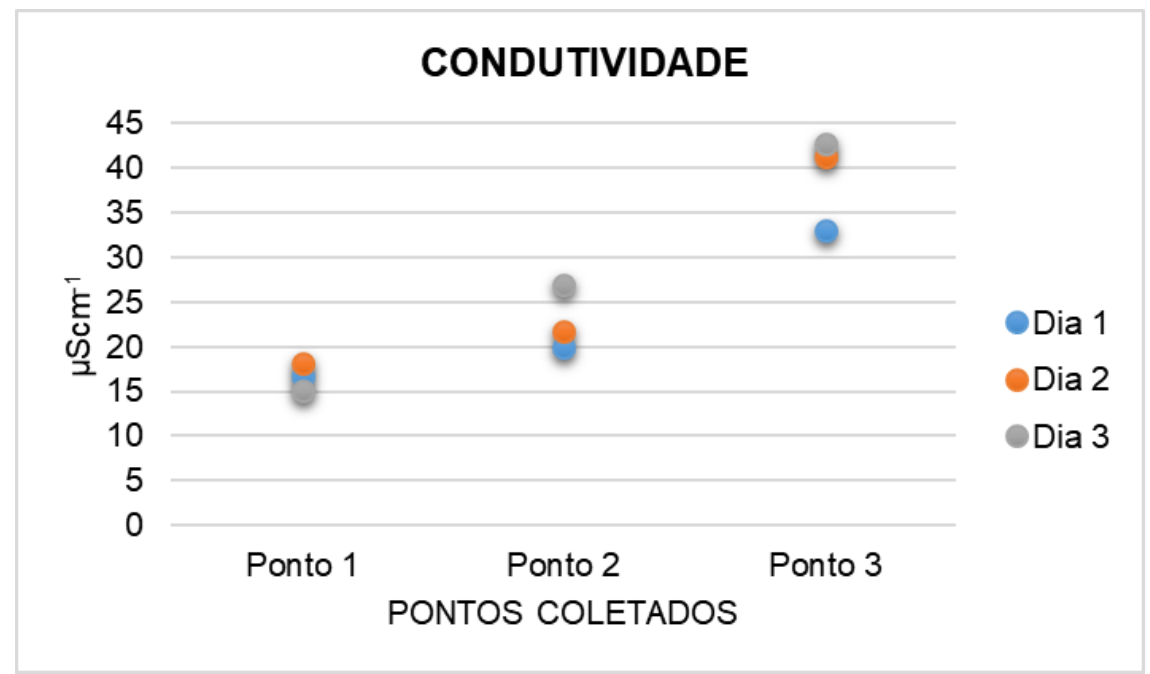

Fonte: Autor, 2018.

Os maiores valores de condutividade são vistos no ponto 3 , nos três dias de análise. No ponto, observou-se o menor valor. O intervalo encontrado nas análises tem valores aproximados ao encontrado por Sousa et. al. (2016), que foi de
13,28 a $32,93 \mu \mathrm{Scm}^{-1}$ para águas condensadas. Para Carvalho, Cunha e Faria (2012), a média da condutividade foi de $20,76 \mu \mathrm{Scm}^{-1}$, valor que está inserido no trecho das amostras coletadas no presente trabalho. 
Os resultados da análise dos sólidos totais dissolvidos (Gráfico 6) das amostras coletadas encontram-se bem abaixo do padrão estabelecido pela ANA (2005), na classe 1 de reúso. A classe 3 não estabelece padrão para este parâmetro.

\section{Gráfico 6: Resultado e comparação do parâmetro sólidos totais dissolvidos}

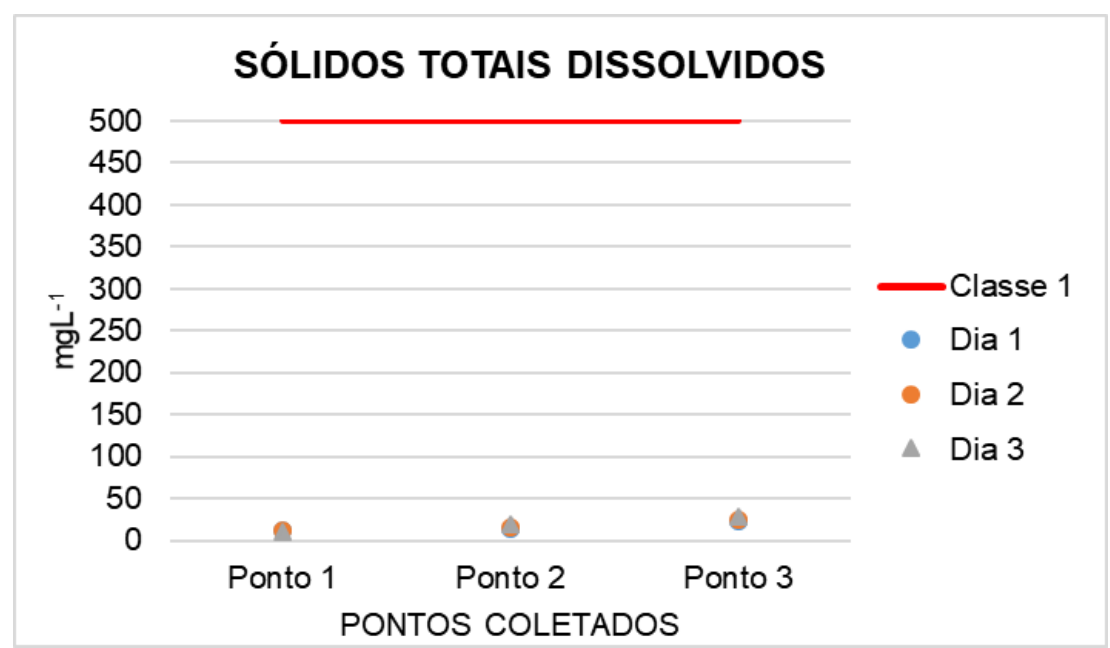

Fonte: Autor, 2018.

O maior valor encontrado para os STD foi o de $29,12 \mathrm{mgL}^{-1}$ no ponto de coleta 3 , sendo o terceiro dia de coleta o que apresentou maiores valores para este parâmetro, nos três pontos analisados; apesar disso, não foram valores muito discrepantes em comparação com os outros dias de análises.
A salinidade (Gráfico 7) não é abordada para as classes de reúso de água 1 e 3 da ANA (2005). Contudo, como já esperado, por se tratar de água condensada, a salinidade de todos os pontos analisados, nos três dias, foi igual a zero.

\section{Gráfico 7: Resultado e comparação do parâmetro sólidos totais dissolvidos}

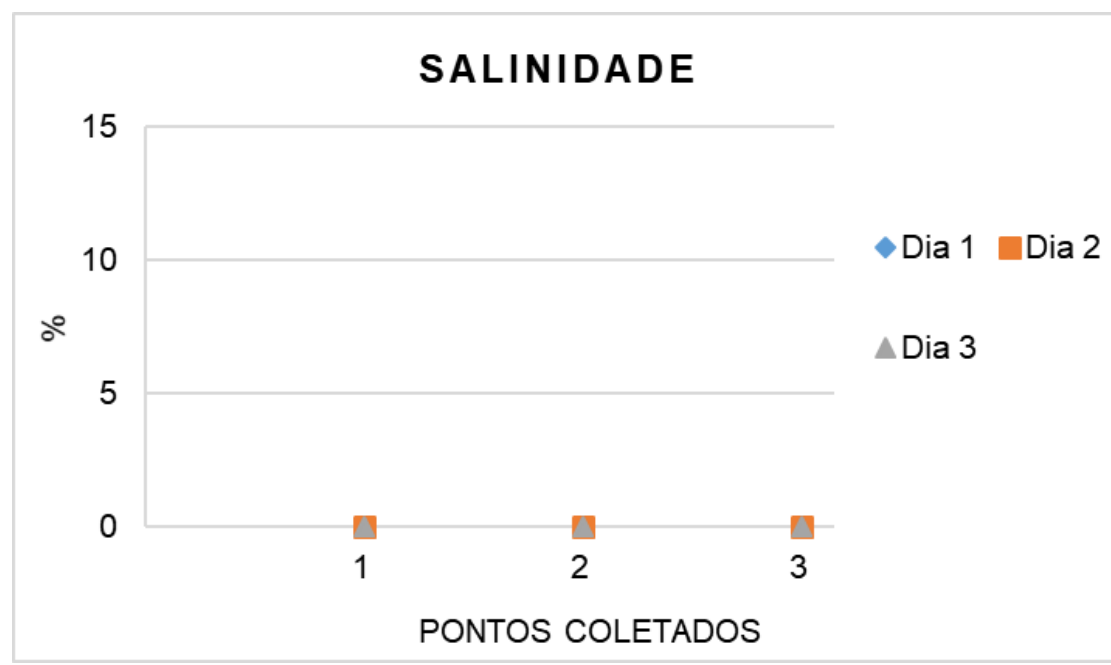

Fonte: Autor, 2018.

De acordo com a ANA (2005), os coliformes termotolerantes, na Classe 1, devem ser ausentes, visto que os usos estabelecidos para esta classe podem fazer com que o público tenha contato com os sistemas de distribuição da água de reúso. Para classe 3 de reuso, a ANA (2005) estabelece o valor máximo de $200 \mathrm{mgL}^{-1}$, sendo este valor o mesmo posto pela OMS para a irrigação de gramados que haja contato direto do público. O resultado das coletas analisadas para o parâmetro microbiológico se deu entre os 
valores de 0 e $132 \mathrm{mgL}^{-1}$, conforme vemos no Gráfico 8.

O ponto 1 apresentou os maiores valores para este parâmetro analisado, contudo, ainda são valores abaixo do estabelecido pela classe 3 de reúso da ANA (2005). Os menores valores analisados na pesquisa situam-se no ponto 2 , tendo os coliformes termotolerantes sido ausentes na análise do terceiro dia. No ponto 3 , pode-se observar que existe um ponto de valor igual a $70 \mathrm{mgL}^{-1}$, contudo, o valor da análise do primeiro dia é de $6 \mathrm{mgL}^{-1}$ e chega a ser ausente no terceiro dia.

\section{Gráfico 8: Resultado e comparação do parâmetro coliforme termotolerantes}

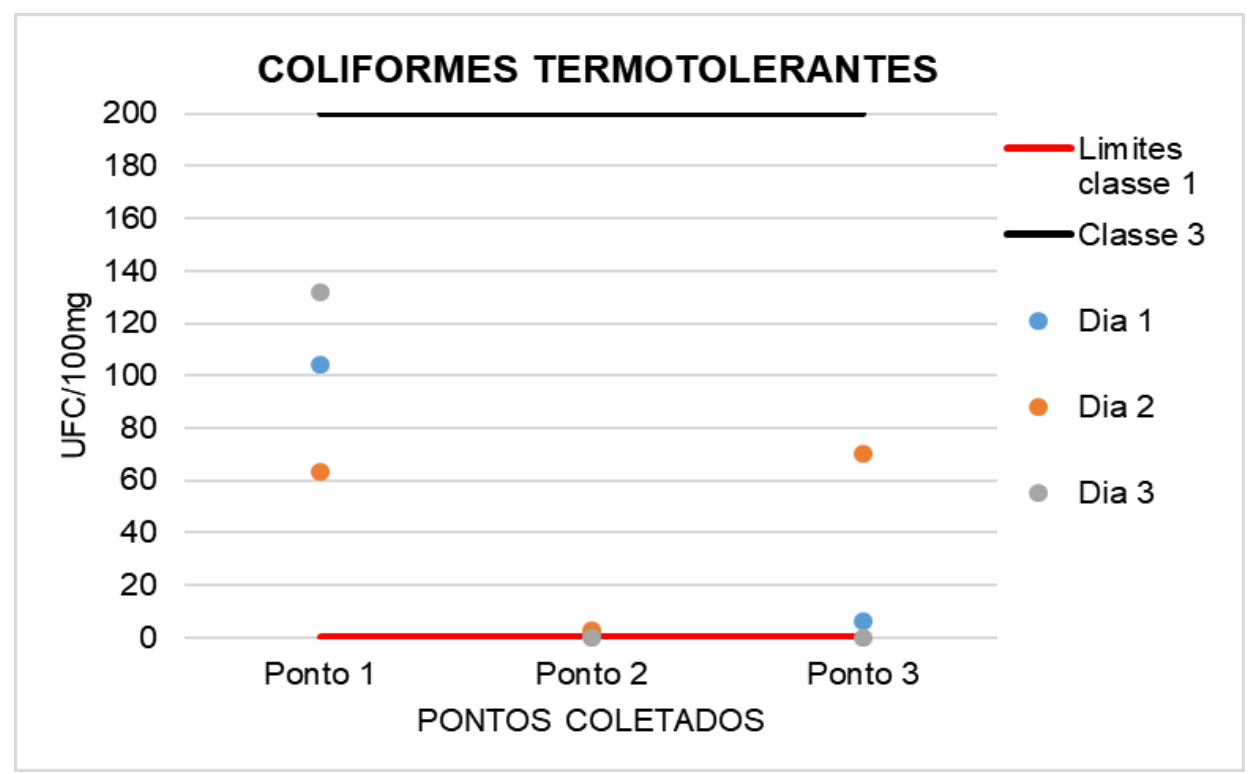

Fonte: Autor, 2018

O ponto 1 avaliado não apresentou nenhuma das análises com coliformes tolerantes ausentes, sendo o dreno do aparelho deste ponto localizado próximo à área vizinha da instituição estudada, área esta formada por vegetação densa e propensa a ser habitat de vários seres-vivos. Com isto, eventualmente, tais seres podem vir a ter contato com o dreno, o que explica a razão da presença de coliformes termotolerantes na água condensada.

\section{CONCLUSÃO}

Com a análise quantitativa do volume gerado de água condensada pelos aparelhos de arcondicionado, pode-se constatar que a potência dos aparelhos influencia de forma direta, posto que, quanto maior a potência do aparelho, maior o volume de água condensada gerado.

$O$ volume mensal da água condensada pelos aparelhos de ar-condicionado da SUDEMA revelou, caso houvesse o aproveitamento, ser possível a redução até $7,5 \%$ do consumo de água oriunda da concessionária de abastecimento e, consequentemente, redução de dinheiro público com a conta de água.
Os valores dos parâmetros analisados na água coletada mantiveram-se satisfatórios em todos os padrões estabelecidos para a Classe 3 (uso para a irrigação de áreas verdes e rega de jardins) do Manual de Reúso de Água em Edificações da ANA. Na Classe 1 (uso para lavagem de pisos, descarga de bacias sanitárias, fins ornamentais, lavagem de roupas e veículos), apenas 0 parâmetro de coliformes termotolerantes ficou em não conformidade com os padrões recomendados.

\section{BIBLIOGRAFIA}

AISSE, M. M; COHIM, E.; KIPERSTOK, A. Reuso Urbano e industrial. In: FLORENCIO, L; BASTOS, R. K. $X$; AISSE, M. M. (Org.). Tratamento e utilização de esgotos sanitários. Rio de Janeiro: ABES, 2006. p. 111-154.

ANA - Agência Nacional de Águas. Detalhamento da Gestão da Oferta na Implantação de Programas de Conservação de Água. Conservação e Reuso da água em Edificações. São Paulo: ANA, 2005. p. 5078. Disponível em: <http://www.fiesp.com.br/indicespesquisas-e-publicacoes/conservacao-e-reuso-de- 
aguas-em-edificacoes-2005/> Acesso em: 19 mai. 2018.

APARELHO PROVÊ ÁGUA A PARTIR DE CONSENSAÇÃO DO AR E NÃO USA ENERGIA OU QUÍMICOS. Portal Tratamento de Água, 9 de dez. de $2016 . \quad$ Disponível em: $<$ https://www.tratamentodeagua.com.br/aparelhoprove-agua-partir-de-condensacao-do-ar-e-nao-usaenergia-ou-quimicos/> Acesso em: 22 abr. 2019.

AQUINO, L. M. Estudo de meios de obtenção de água potável a partir da condensação da umidade do ar. 2018. Monografia (Engenharia Mecânica) Escola Politécnica, Universidade Federal do Rio de Janeiro, Rio de Janeiro, 2018.

BASTOS, C. S.; CALMON, J. L. Uso de água residual do ar-condicionado e de água pluvial como gestão da oferta em uma edificação comercial: estudo de caso. Revista Hábitat Sustentable, Chile, v. 3, n. 2, p. 6674, dez. 2013. Semestral.

CASSINI, S. T. A.; FRANCI, R. Gestão da água em edificações através do aproveitamento de condensação do sistema de ar-condicionado: um exemplo em Vitória, Brasil. In: LATIN-AMERICAN AND EUROPEAN CONFERENCE ON SUSTAINABLE BUILDINGS AND COMMUNITIES, 1., 2015, Guimarães. Anais... Guimarães-PT: Universidade do Minho, 2015. p. 1197-1201. Disponível em: $<$ http://civil.uminho.pt/Euro-ELECS-2015/files/Euro-

ELECS 2015-Proceedings Vol2.pdf> Acesso em: 24 abr. 2019.

BRASIL, Lei № 9.433, de 8 de janeiro de 1997. Institui a Política Nacional de Recursos Hídricos e cria o Sistema Nacional de Gerenciamento de Recursos Hídricos. Diário Oficial da República Federativa do Brasil, Poder Legislativo, Brasília, DF, 09 jan. 1997. p. $470 . \quad$ Disponível em: <http://www.planalto.gov.br/ccivil 03/leis/L9433.htm> Acesso em: 22 abr. 2018.

CALDAS, J.; CAMBOIM, W. L. L. Aproveitamento da água dos aparelhos condicionadores de ar para fins não potáveis: avaliação da viabilidade de implantação em um bloco do Unipê. Revista InterScientia, João Pessoa, v. 5, n. 1, p. 166-188, 2017. Semestral. Disponível em:

$<$ https://periodicos.unipe.br/index.php/interscientia/articl e/view/464> Acesso em: 24 abr. 2019.

CARVALHO, M. T. C.; CUNHA, S. O.; FARIA, R. P. P. G. Caracterização quali-quantitativa da água da condensadora de aparelhos de ar-condicionado. In: CONGRESSO BRASILEIRO DE GESTÃO AMBIENTAL, 3., 2012, Goiânia. Anais... Goiânia-GO.: PUC, $2012 . \quad$ Disponível em: $<$ http://www.ibeas.org.br/congresso/Trabalhos2012/IX002.pdf $>$ Acesso em: 30 abr. 2018.

CAMARGO, S. Caçador de nevoeiro: conheça a história de Abel Cruz, que captura água do céu para comunidades pobres de Lima. Conexão Planeta, 8 de dez. de 2016. Disponível em: $<$ http://conexaoplaneta.com.br/blog/cacador-denevoeiro-conheca-a-historia-de-abel-cruz-que-capturaagua-para-comunidades-pobres-de-lima/>Acesso em: 22 abr. 2019.

Holandês cria turbina eólica que produz água potável. Exame, 8 de ago. de 2014. Disponível em: $<$ https://exame.abril.com.br/tecnologia/turbina-eolicaproduz-agua-potavel/> Acesso em: 22 abr. 2019.

CATAPRETA, C. A. A.; FREITAS, A. S. Estudo de viabilidade para aproveitamento da água de condensação de máquinas de ar condicionado. In: CONGRESSO NACIONAL DE SANEAMENTO E MEIO AMBIENTE, 28., 2017, São Paulo, Anais... São PauloSP: ABES e AESabesp, 2017.

GONÇALVES, R. F.; JORDÃO, E. P.; JANUZZI, G. Introdução, In: (Org.). Uso racional de água e energia: conservação de água e energia em sistemas prediais e públicos de abastecimento de água. 1. ed. Rio de Janeiro: ABES, 2009. p. 21-35.

HESPANHOL, I. Potencial de reuso de água no Brasil: agrícola, indústria, município e recarga de aquífero. In: MANCUSO, P. C. S; SANTOS, H. F. (Org.). Reuso de Água. Barueri: Manole, 2003. p. 37-95.

LIMA, P. C. C.; SANTOS, R. A.; RIBEIRO, M. C.; MACHADO, V. T. Projeto de captação de água dos aparelhos de ar-condicionado para o uso não potável na faculdade Santa Maria-FSM. In: CONGRESO ASOCIACIÓN LATINOAMERICANA DE SOCIOLOGÍA, 31., 2017, Montevideo. Anais... Montevideo-Uruguay: Asociación Latinoamericana de Sociología, 2017. Disponível em: $<$ http://alas2017.easyplanners.info/opc/tl/1945 pavlova christinne cavalcanti lima lima.pdf> Acesso em: 24 abr. 2019.

NÓBREGA, J. M. S. Água residual de condensadores de ar: perspectiva de substituição à água destilada para uso em laboratórios. 2015. Monografia (Graduação em Ciências Biológicas) - Universidade Federal de Campina Grande, Patos, 2015.

OUTDOOR TRANSFORMA AR EM ÁGUA PARA BEBER. Portal O Tempo, 25 de março de 2013. Disponível em $<$ https://www.otempo.com.br/brasil/outdoor-transformaar-em-\%C3\%A1gua-para-beber-1.224439 >Acesso em: 22 abr. 2019.

PARAÍBA. Lei № 10.559, de 18 de novembro de 2015. Dispõe sobre a Instituição da Campanha Permanente de Mobilização Estadual contra o Desperdício de Água no Estado da Paraíba e dá outras providências. Diário Oficial do Estado da Paraíba, João Pessoa, PB, 19 nov. 2015. n. 15.984, p. 1.

RIGOTTI, P. A. C. Projeto de aproveitamento de água condensada de sistema de condicionadores 
de ar. 2014. Monografia (Graduação em Engenharia Mecânica) - Universidade Regional do Noroeste do Estado do Rio Grande do Sul, Panambi, 2014.

ROCHA, D. P. B. Sistema de reuso de água proveniente de aparelhos de ar condicionados para fins não potáveis: estudo de caso aplicado ao Centro de Tecnologia da UFRN. 2017. Monografia (Graduação em Engenharia Civil) - Universidade Federal do Rio Grande do Norte, Natal, 2017.

SOUSA, R. E. B.; ROCHA, C. M. S.; ABREU, F. O. M. S.; MORAES, S. G. Caracterização físico-química e microbiológica das águas condensadas de aparelhos de ar-condicionados visando potencial reutilização.

Revista Tecnologia, Fortaleza, v. 37.1. p. 37-54, $2016 . \quad$ Disponível em: <https://periodicos.unifor.br/tec/article/view/5700>

Acesso em: 6 abr. 2019.

SOUSA, W. D.; OLIVEIRA, A. M. B. M.; COELHO, L. F. O. Aproveitamento do potencial hídrico de fontes alternativas em benefício da sustentabilidade de campus universitário da cidade de Pombal (PB). In: CONGRESSO BRASILEIRO DE GESTÃO AMBIENTAL, 7., 2016, Campina Grande. Anais... Campina Grande-PB: Universidade Federal de
Campina Grande, 2016. Disponível em: $<$ https://www.ibeas.org.br/congresso/Trabalhos2016/l045.pdf> Acesso em: 6 abr. 2019.

SOUZA, F. Engenheiro de São Paulo inventa máquina que 'fabrica' água. Folha de S. Paulo, São Paulo, 12 de out. 2014. Disponível em: <https://www1.folha.uol.com.br/cotidiano/2014/10/1531 155-engenheiro-de-sao-paulo-inventa-maquina-quefabrica-agua.shtml?cmpid=\%22facefolha\%22> Acesso em: 24 abr. 2019.

WEATHERBASE. Clima, 22 de abr. de 2019. Disponível em: $<$ https://www.weatherbase.com/weather/weathersummary.php3?s=89728\&cityname $=\mathrm{Joao}+$ Pessoa $\% 2 \mathrm{C}$ +Paraiba\%2C+Brazil\&units=> Acesso em: 22 abr. 2019.

WWAP - World Water Assessment Programme. Relatório mundial das Nações Unidas sobre o desenvolvimento dos recursos hídricos, 2017: Aguas residuais: o recurso inexplorado, resumo executivo. Unesco, 2017. p. 12. Disponível em: $<$ http://unesdoc.unesco.org/images/0024/002475/ 247552por.pdf> Acesso em: 19 mai. 2018. 